\title{
RESULTS OF AUTOMATIC IDENTIFICATION OF TRANSPORT UNITS IN POSTAL ENVIRONMENT
}

\author{
Juraj Vaculík, Peter Kolarovszki, Jiří Tengler \\ University of Zilina \\ Faculty of Operation and Economics of Transport and Communications \\ Department of Communications \\ Univerzitná 1, 010 26, Slovakia \\ Ph.+421908227492.E-mails: juvac@fpedas.uniza.sk,peter.kolarovszki@fpedas.uniza.sk, \\ jiri.tengler@fpedas.uniza.sk
}

This article primarily deals with identification of postal items and transport units in the logistic chain of postal operators. Nowadays, the identification is carried through barcodes and optical character recognition. In this article we would like to specify, how the transport units can be identified in the transmission process by RFID technology. In the carriage of postal items it is necessary to decide what type of transport is used for that purpose, what the flows of items are and what their intensity is. The RFID technology is complex, combining a number of different computing and communication technologies to achieve the desired objectives. Each object, which has to be identified, is stuck inside of a small object known as an RFID tag. RFID tag has a unique identifier, through which you can store additional information about the object. Equipments which are known under the name of RFID readers wirelessly, communicate with RFID tags with a view to identify RFID tags attached as well as the possibility to read and update information stored in the RFID label.

The article describes the scheme of the transport process, including planned technology and there is also simulated a real postal process in conditions close to operational.

Keywords: RFID technology, Transport unit, Transportation, Postal items

\section{Introduction}

An unavoidable part of today is a dynamic development in the field of mobile technologies, their everyday use and application of the processes, which largely support the level of the quality of postal services and thereby strengthen the market positions of individual postal operators. This area is even more pertinent that in all countries of the European Union since the $1^{\text {st }}$ of January, 2013 approved the postal market and postal services. In this respect, it is necessary to include the postal processes embarked on new technologies to ensure the competitiveness of the national postal operator and the alternative providers.

RFID technology has been selected by an international post corporation (IPC) to test deliverability (transit time) of items in 55 countries of the world (Slovak republic including). The requirement of transit time is defined by the Universal Postal Services and applicable also for Slovak Post. Despite the RFID technology is being known and being improved for a long time, it is essential to define the standards and security requirements.

Besides efficiency, consolidation and globalisation within the European Union, interoperability is one of key elements. It is the ability of information and communication systems (including the supported processes) to exchange data, share information and knowledge, which lead to standardization.

\section{Objective and Methodology}

To understand the problem it is appropriate to analyse the various terms used. With the current availability of individual components of RFID, GPS devices and the possible use of the possibilities of satellite navigation, we can create quite a purposeful infrastructure and improve the traffic management of the postal processes.

Despite the fact that the personal correspondence is given to the development of information technologies and the Internet on the decline and supporting interest in use of the postal services to business correspondence, the postal services are and will remain an essential part of the society.

Taking into account all these contexts, external influences on the postal sector and the potential of the existing technologies from the perspective of the thesis it is important to analyse the possibilities for automation of the processes, streamlining operational activities and transportation to ensure continuity in meeting the objectives of customer satisfaction in the field of postal services, particularly in the delivery of consignments. The paper defines and points out the possible improvements in this area. 


\subsection{Mobile Technology}

The classification of wireless technologies, based on the distance or range of the transmitted signals, provides insight into their potential use. Condition for the data transmission in the wireless systems and communication networks is not fixed connection cable. One possible distribution system is under the coverage:

- Global Systems - cover wide scale spatial coverage, it is possible to talk about the world operating systems, which are not dependent on the particular application and data transfer takes place in various protocols (e.g., the satellite communication systems, GPS);

- Metropolitan systems - operate in a lower geographical unit, usually on the national level (such as systems based on the microwave technology, WiFi);

Local systems - ranging from the order of centimetres to hundreds of meters (Bluetooth, RFID).

\subsection{Postal Transport Network}

The postal transport is an important part of the process of filing a postal item to its delivery to the addressee in compliance with established quality standards for different types of mail under postal license requirements and the quality of universal postal service.

The postal transmission network consists of the road transport routs and road itinerary. The structures of the postal transmission network use various tools and systems. The postal transport network is currently divided into three main levels:

- district transport network (OPS) - connects the establishment and other facilities on the territory of the district processing centre and regional units $(\mathrm{OU})$ with the delivery points,

- regional transport network (RPS) - connects the main processing centres in regional processing centres with their own circuit, the main processing centres with appropriate regional nodes, where the regional processing centres are,

- the main transport network (HPS) - connects the major processing centres, the main processing centres with regional processing centres from another circuit HSS, including the transport findings in the international relations.

In the carriage of postal items it is necessary to decide what type of transport is used for that purpose, what are the flows of items and what is their intensity. The way to connect and the type of the vehicle depend on the following factors:

- density and organization of the postal network,

$\circ$ flows of different types of postal items and their size,

$\circ$ the carrying capacity of the vehicles used,

- transport time of each species of postal items,

- safety and effectiveness of the postal traffic.

Processing of items is implemented in the workplace of the Slovak Post:

- $\quad$ HSS - the main processing centre - the facility providing treatment and quest items posting its area of perimeter, mail items addressed to your district and in transit in its dealings with OSS circuit, in contact with other HSS and OU,

- OSS - the regional processing centre - the post office responsible for preparing and quest items posted at post offices in his own constituency and in transit in contact with your postal district and interacted with the HSS, the facility responsible for receiving, processing and questing items express postal services,

- $\quad$ selected post - the post office responsible for preparing and questing items selected species within a specified range (usually as OSS),

- Exchange post - processing the shipment and ensuring shipments to post offices exchange foreign postal administrations,

Regional hub as a department of express service - establishment is responsible for receiving, processing and questing items express postal service.

\subsection{Characteristics of Transport Units and Processes}

Characteristics of transport units - Slovak Post, a. s. used in the transport process shipments following shipping units: containers, leaf containers and postal bags. Containers are used in the transport process at HSS and OSS, on the local network using only postal letter case and postal bags. 
The basic flows of transport processes are shown on Figure 1 including the use of a basic mobile technology on the relevant stages.

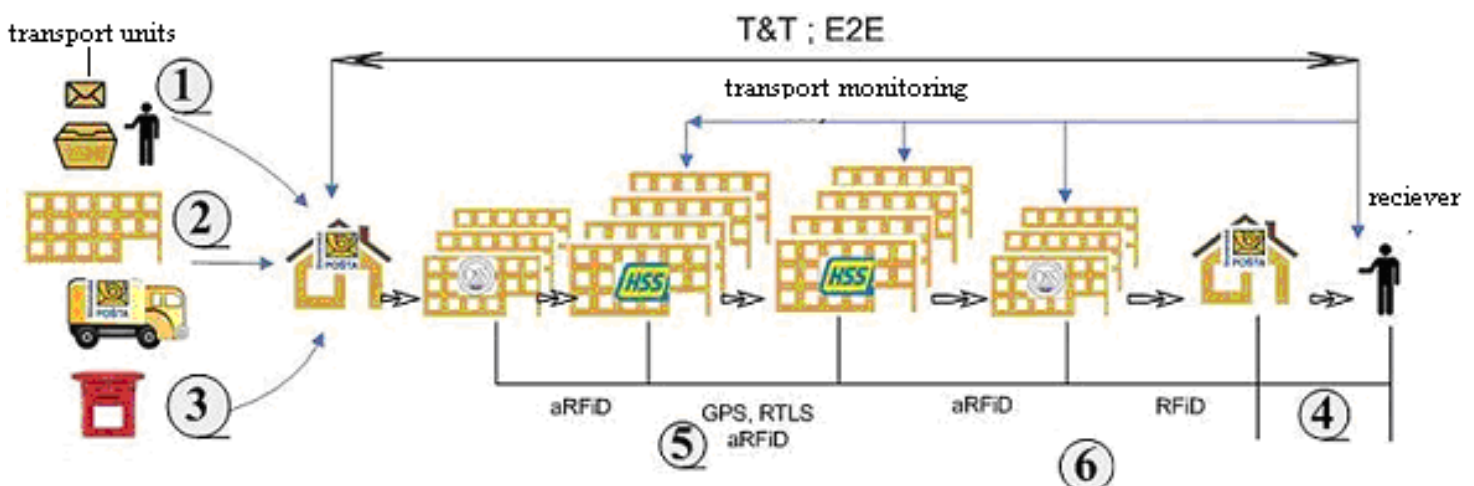

Figure 1. Scheme of the transport process, including the planned technology
1. sender pass the post office at the counter,
2. collecting expedition posting or accumulating courses,
3. pass through postal box,
4. mobile technology - monitoring the transport process,
5. possibilities for optimising routes for mail delivery,
6. communication with the addressee.

\section{RFID Technology}

Radio frequency identification is a wireless data collection technology that uses the electronic tags which store the data, and the tag readers which remotely retrieve the data. It is a method of identifying the objects and transferring information about the object status via the radio frequency waves to a host database. RFID is not necessarily a direct replacement for the bar codes, but as the costs of RFID systems continue to decrease, the functional utility of RFID will greatly surpass that of bar codes. [7]

An RFID system is a set of components that work together to capture, integrate, and utilize data and information. This section describes some of them. The components are as follows:

- Sensors, Tags, Antennae, Readers.

- Connectors, Cables, Networks, Controllers.

- Data, Software, Information Services.

\subsection{RFID Tags}

An RFID tag is a small device that can be attached to an item, case, container, or pallet, so it can be identified and tracked. It is also called a transponder. The tag is composed of microchip and antenna. These elements are attached to a material called a substrate in order to create an inlay. [8]

Tags are categorized into three types basing on the power source for communication and other functionality.

- A passive tag uses the electromagnetic energy and it receives from an interrogator's transmission order to reply to the interrogator. The reply signal from a passive tag, which is also known as the backscattered signal, has only a fraction of the power of the interrogator's signal. This limited power significantly restricts the operating range of the tag. Since passive tags are low power devices, they can only support data processing of limited complexity. On the other hand, passive tags typically are cheaper, smaller, and lighter than other types of tags, which are compelling advantages for many RFID applications.

- An active tag relies on an internal battery for power. The battery is used to communicate to the interrogator, to power on-board circuitry, and to perform other functions. Active tags can communicate over greater distance than other types of tags, but they have a finite battery life and are generally larger and more expensive. Since these tags have internal power, they can respond to lower power signals than passive tags. 
- A semi-active tag is an active tag that remains dormant until it receives a signal from the interrogator to wake up. The tag then can use its battery to communicate with the interrogator. Like active tags, semi- active tags can communicate over a longer distance than passive tags. Their main advantage relative to active tags is that they have a longer battery life. The waking process, however, sometimes causes an unacceptable time delay when tags pass interrogators very quickly or when many tags need to be read within a very short period of time.

- A semi-passive tag is a passive tag that uses a battery to power on-board circuitry, but not to produce return signals. When the battery is used to power a sensor, they are often called sensor tags. They typically are smaller and cheaper than active tags, but have greater functionality than passive tags because more power is available for other purposes. Some literature uses the terms "semi-passive" and "semi- active" interchangeably.

\subsection{RFID Reader}

The second component in a basic RFID system is an interrogator or reader (Figure 4). Readers can have an integrated antenna, or antenna can be separate. The antenna can be an integral part of the reader, or it can be a separate device. Handheld units are a combination of reader/antenna, while the larger systems usually separate the antennae from the readers. The reader retrieves the information from the RFID tag. The reader may be self-contained and record the information internally; however, it may also be a part of a localized system such as a POS cash register, a large Local Area Network (LAN), or a Wide Area Network (WAN). [6]

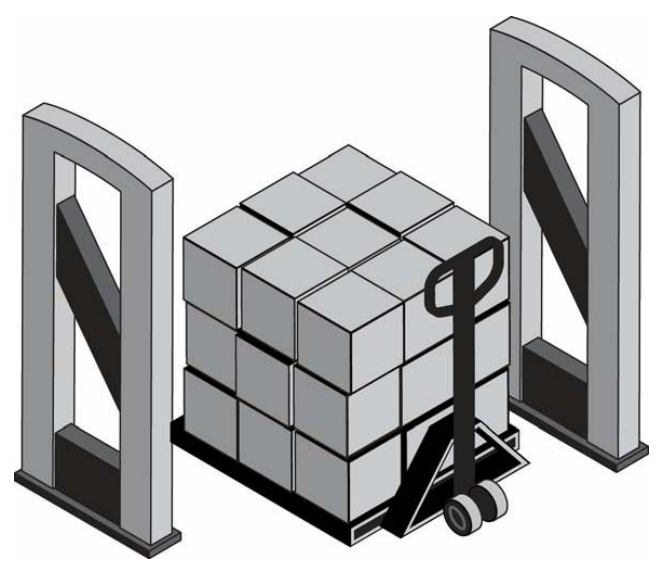

Figure 2. Stable RFID reader

\section{Model and Test of Readability of Postal Items through the RFID Technology}

One of the methods that could significantly make the process of identifying the postal items in transport condition effective is just a RFID technology. As a wireless technology, without visual contact with the shipment, it tracks and identifies the contents without the need of manual handling from the crate. This allows easier and more efficient handling of supporting documents (creating the list of items, checking the presence of item) of postal sacks/bags and containers. With regard to price and the quantity of item processes, a question arrives: Is RFID technology effective and should be used for all shipment, including letters? As it has already been mentioned, due to the large quantities of common items and still relatively high price of tags the method could be real only for the registered mail. The actual implementation design of RFID technology, as it is shown on Figure 3 could be divided into the following phases:

1st phase - tracking between the HSS

2nd phase - tracking between the HSS and OSS.

3rd phase - tracking between the OSS and final post office (point of delivery).

Because of the fact that our basic interest lies in the RFID technology we have tried to test the readability of the RFID tags placed on the postal items in various situations. The basic assumption is the use of RFID gates at the entrance and output of the processing unit as it is shown on the following Figure. 

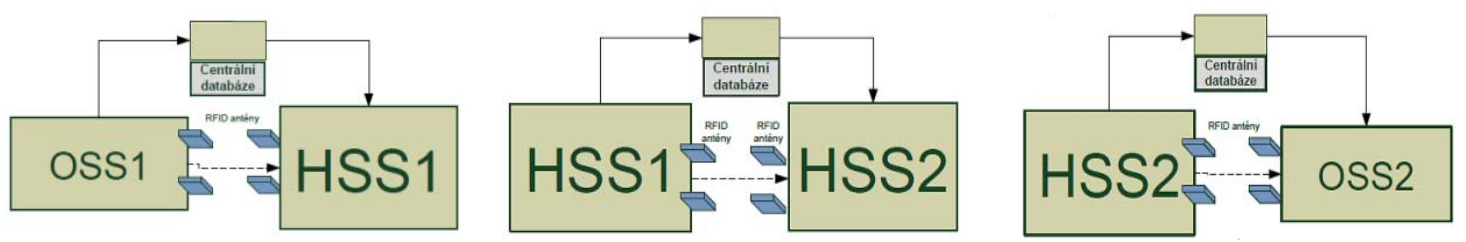

Figure 3. RFID gates at the entrance and output of the processing unit

In order to verify the practical applicability of this technology, we have dealt with the preparation and implementation of the practical activities through which we have examined reading RFID tags. The objective of these measurements was to determine the statistical characteristics of reading success and reading passive tags, placed on postal items, located in the mail bag. The aim was to provide sufficient information, accurately measured under the different conditions that can occur in a real situation, including a draft measure, which would lead to the improvement of the measured data.

Therefore, we try to simulate a real postal process in conditions close to the operational ones, and test this technology on next component set configuration:

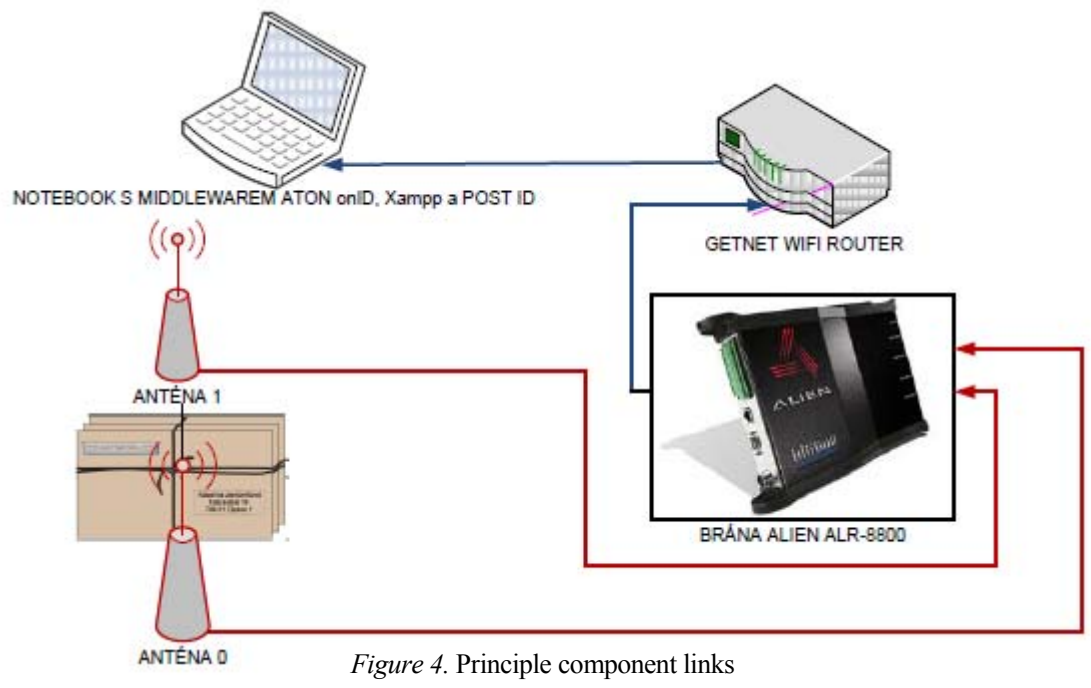

When entering the volume or volumes placed in the transport unit to the detector array there is a transfer of identification data of RFID tags through the RFID gate antennae in which the process and with further data. These data, the number of antennae in particular, have a specific identifier and retrieve the operational information in the form of door type. Thus the processed data are transmitted through the wifi router middleware Aton on ID in a notebook.

Here is primarily the communication between web applications POST ID, MySQL database server and middleware on ID Aton. The principle of the software components and their cooperation can be understood from the Figure located in the next section.

\subsection{Description of the Model and middleware Aton on ID}

There was used a software from Italian company Aton, also known as a middleware, which provides the management, organizational and communication operations between different applications. In our case, they are the firmware Alien Gate and other applications, particularly database server. On ID Aton itself is not a monolithic program, but it is a functional connection Java service console (java server) and the graphic manager called Qflow. Qflow itself is intuitively and easily enabled in an interactive creation and administration of the custom processes.

One of the most important parts of the model, which it was used to measurement, was RFID middleware together with RFID devices. And that is the reason, why we describe better this special software. As it has been said, this middleware isn't monolithic program but functional connection more applications and modules, which are controlled by certain rules. The execute module of this software is Java server, which is currently a work gear for other modules. All operations are performed through this server. Each change and communication between modules is displayed at the console, which is a part of Java 
server. This part provides information only. There is mean information about errors or wrong settings of different modules. It can refer as control part of middleware.

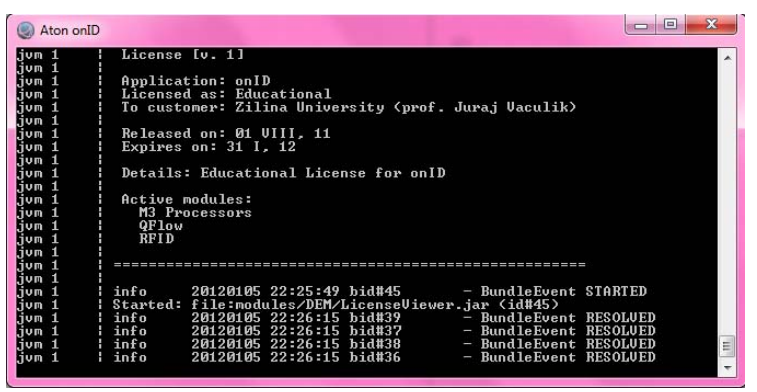

Figure 5. Console on ID

As mentioned in the introduction of this part section, middleware has two modules Qflow and Qview. As the name applies, qview is module, which is used to display to basic value from measurement with RFID devices.

This module isn't of great importance and this is the reason, why we will deal by Qflow module in this article. Qflow we can be identified as user module, because there can be set as follows:

- basic parameters and mode of communication between middleware as a whole and connected RFID device,

- transmission and communication control between different devices and programs,

- own application group (there is mean formation communication and functional elements, which are known as processors).

Description of Qflow and its logics.

This module is a graphical interface, which is composed of menu of module and application functional area of module.

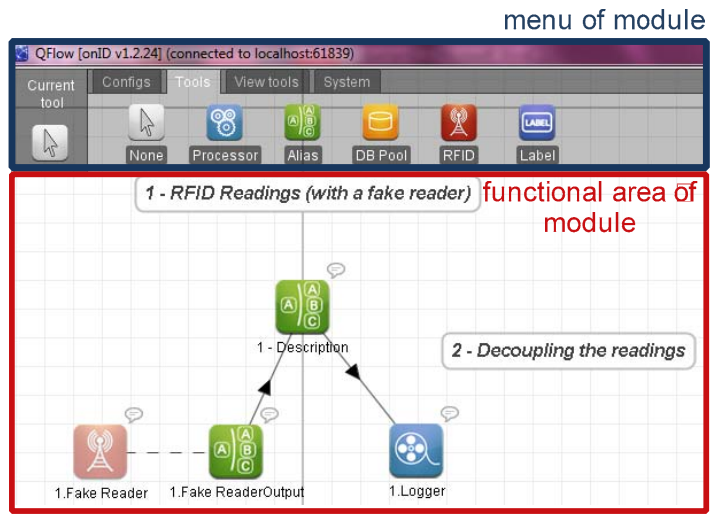

Figure 6. Menu of module

This menu is composed from 4 parts:

The first part is used to load, save and reset created functional group of processors (elements).

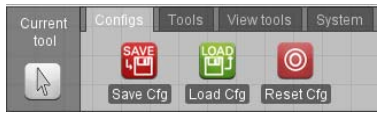

Figure 7. Configuration buttons

The second part is contained of individual functional processor, which is directly used for creating the above-mentioned functional group. More important are flag Processors but these will be described further.

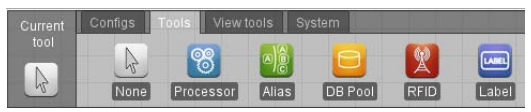

Figure 8. Tools of onID 
The third part consists of element to support of manipulation with elements, which we mentioned in the part 2.

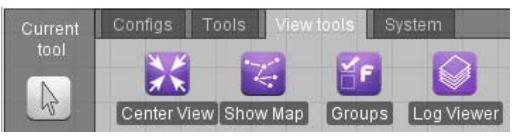

Figure 9. View tools

The last part is used to safe termination of middleware.

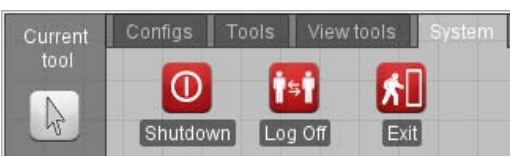

Figure 10. System tools

Creating of application connection of element is carried very simply through flag processors. After activation of this flag it shows menu of processors. This menu contains a lot of type processors and processors families, which have different function and purpose. After selecting and confirmation of this order, processor of functional area of network is created, which can be seen on Figure 11.

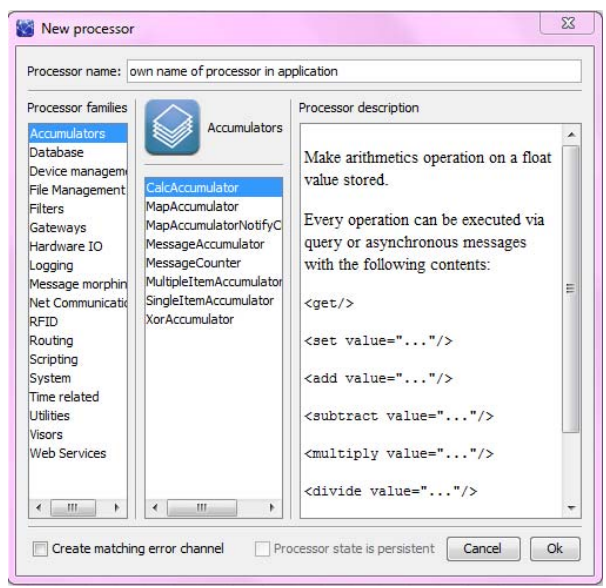

Figure 11. Menu of processors

Each processor has its own menu, which can be seen on Figure 12.

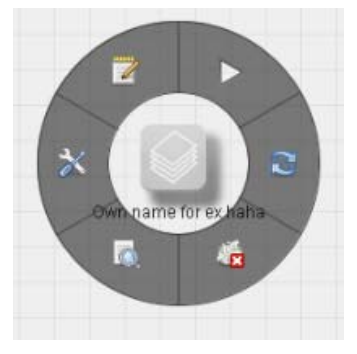

Figure 12. Menu of processors

Menu contains the following elements:

- start processor/stop processor,

- reload of processor,

- delete this processor,

- view to xml settings of processor,

- setting of processor,

- hidden comments of processor.

A lot of processors need to proper operation specifics setting of processor parameters. And this is performed through processors menu ,setting of processor“.

After selection of setting, order of processor parameter with pre-defined parameters is showed. 


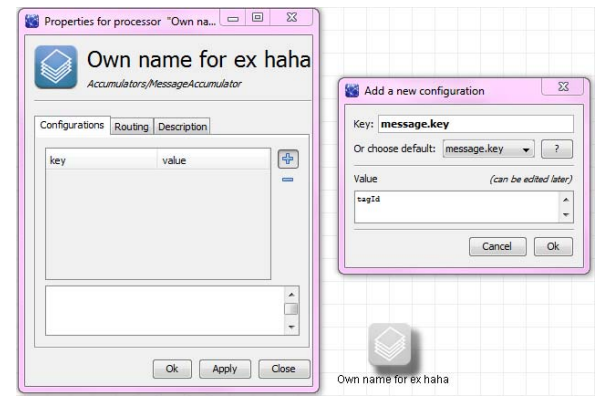

Figure 12. Settings of processors menu

After selecting the required processors and their settings, there is a need to create logical communication between these processors. All communication is realized through Xpath language (XML Path Language). Xpath is a query language for selecting nodes from an XML document. This language allows selecting from XML document individual elements and working with their values. And this means work with processor parameters in middleware. The logics there remind water pipes with set flow direction and processor indicate place, where to flow XML information is inserted. The connection is created through dragging mouse cursor from the first to the second processors. This direction of the drag is equal direction of flow. After connected by needed processors it is necessary to activate all processors in processor menu through flag ,start“.

Through similar activities application is created, which is used to listen below obtained results.

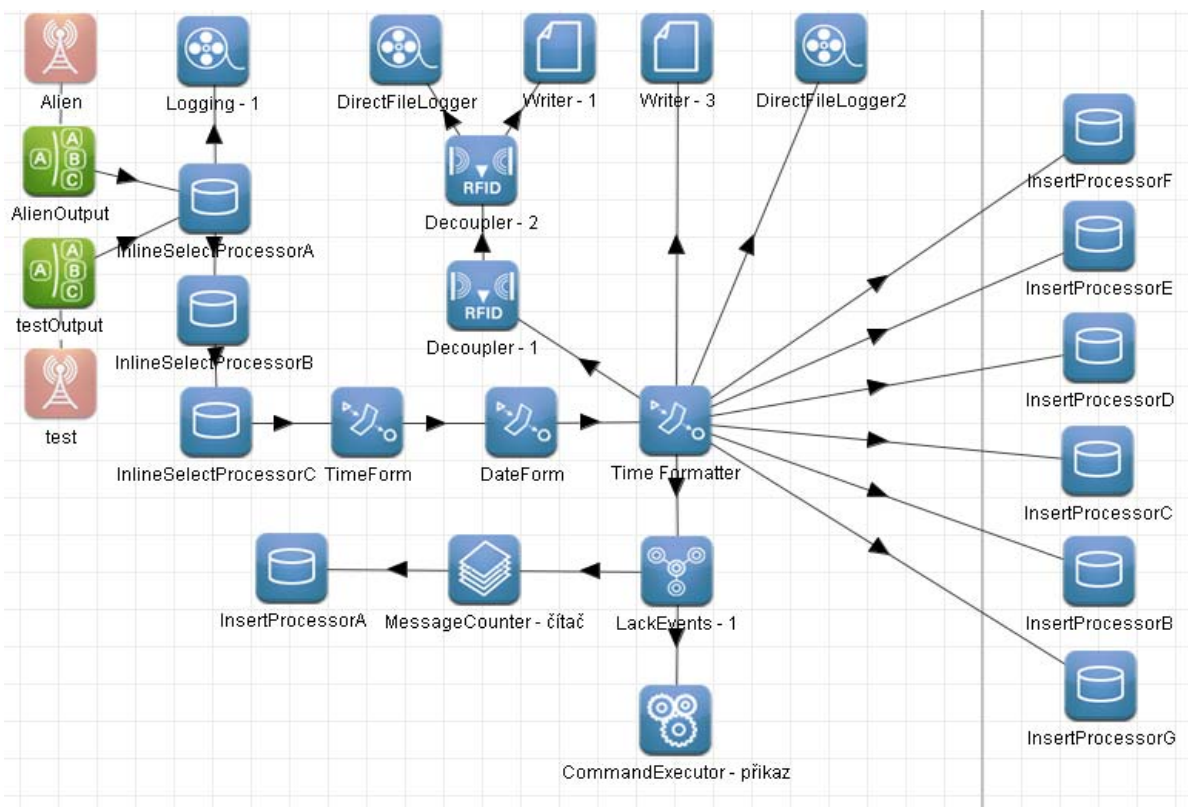

Figure 13. Configuration model

The major elements are the program elements, called the processor to implement elementary operations (reading from the gateway, filtering, recording the output, etc.)

- The first step is to enter the configuration data to POST ID. From there it must be deposited directly into the database tables. The subject of this storage is data on the number of configuration items and numbers.

- In a second step, after the start of broadcasting the alien elements and their detection by Inline Processor, load measurement numbers, the number of items and the configuration numbers are made and then they are attached to the information from the antennae.

- The third step is to report the detection of these data; it enriches the timing parameters through the Time Formatter processors, and cumulative data travel up to 4 lines. The first two travel into the generators of the text and $\mathrm{xml}$ files according to the uniqueness of the registration data. The third way is into the InsertProcessor, where the data are entered into the database. The fourth way turns itself to the LackEvents processor. In case if there is no new messages from the gateway 
recorded in the determined period of time, it sends a new message to next two processors, which increase the value of the measurement number by 1 on the basis of the received message (MessageGenerator) by updating the database InsertProcessorA.

- The second Command Executor processor on the receipt of a report indicates the new number of measurements by running the alarm. The measurement consists of setting values in POST ID and physical adjustment of antennae. There has been an effort done for making sure if it is possible to have the most accurate and smoothest possible transition from beginning to end of the runway. After making the transition it is necessary to wait for the time needed for detection of zero, which means the CPU and Lack Events Command Executor sounds, indicating the end of the measurement and readiness for the next measurement. At the same time, the processor Message Counter increases the number of the first measurement after finishing the sound detection, and it is possible to make the switch between the antennae to the selected track again.

Full application part is shown on Figure 14.

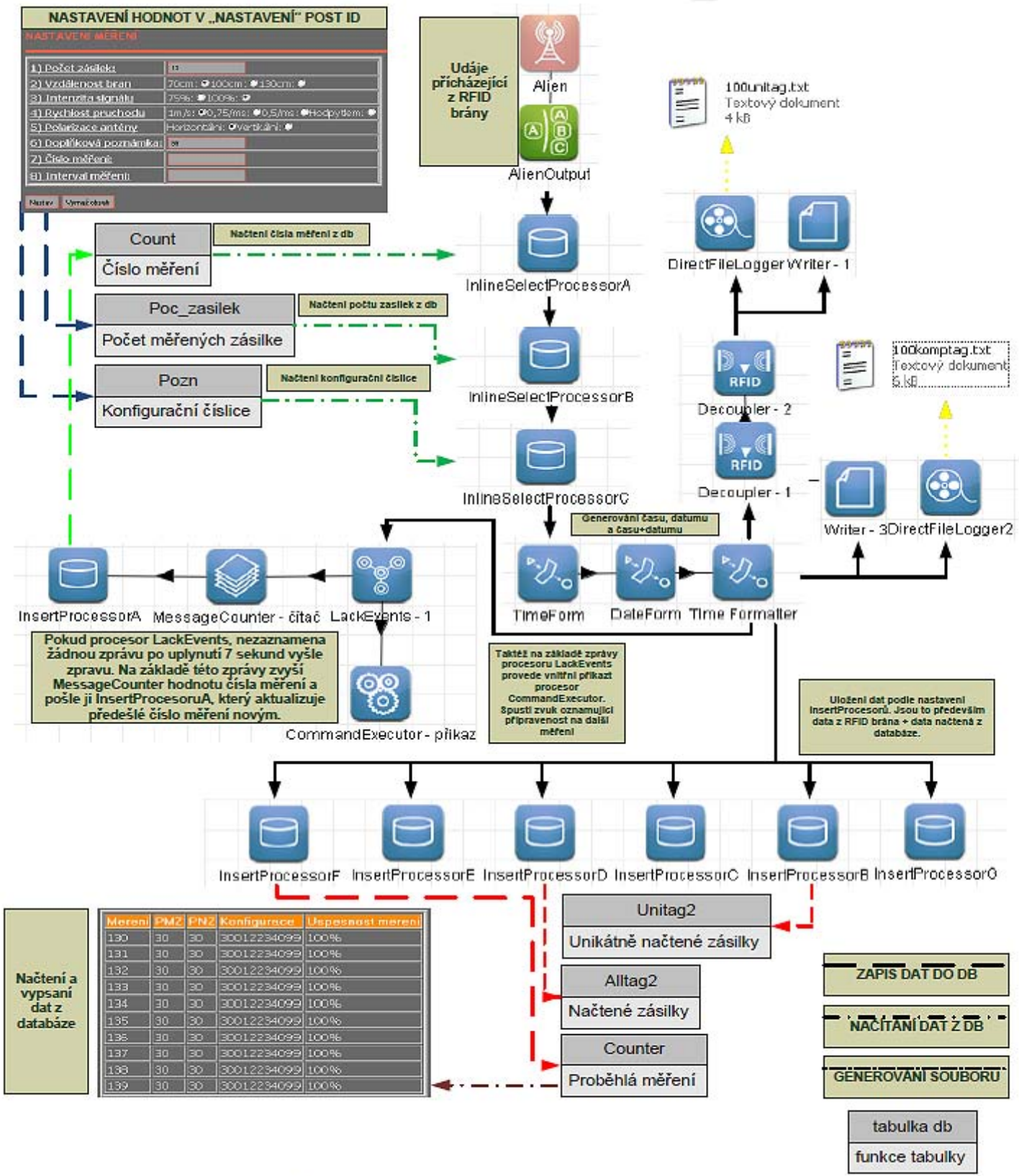

Figure 14. Final configuration model based on ATON on ID 


\subsection{Test of Readability of Postal Items}

Measurements have been carried out in an improvised laboratory in the premises of the computer lab of the University of Žilina. There were measured the passive tags placed uniformly on all mail in the middle of the upper left corner. Tags were placed so strictly because the challenging situation that could occur in real practice was simulated, so that all shipments under the labels overlap, the close neighbours. This arrangement could cause the EM waves emitted by RFID tags to interfere with each other. For each item there was then transcribed a RFID tag number and a serial number marked for easier later processing the statistical information. The objects of the measurement items were deposited into the mail bags, which are grouped into a bundle. To determine the characteristics of reading and expanding, sub-measure was introduced by another character, and that is the position of the beam due to the antennae. These positions are defined (according to Figure 15):

1) boundle horizontally - the length of the area enclosing antennae,

2) boundle horizontally - the width of the area enclosing antennae,

3) boundle vertically - party address shipments parallel flat antennae,

4) boundle vertically - mail address side perpendicular to the plane antenna.

Likewise, our measurements were sequenced according to the serial number of items, grouped into bundles, according to the size of the consignments as shown on Figure 16.
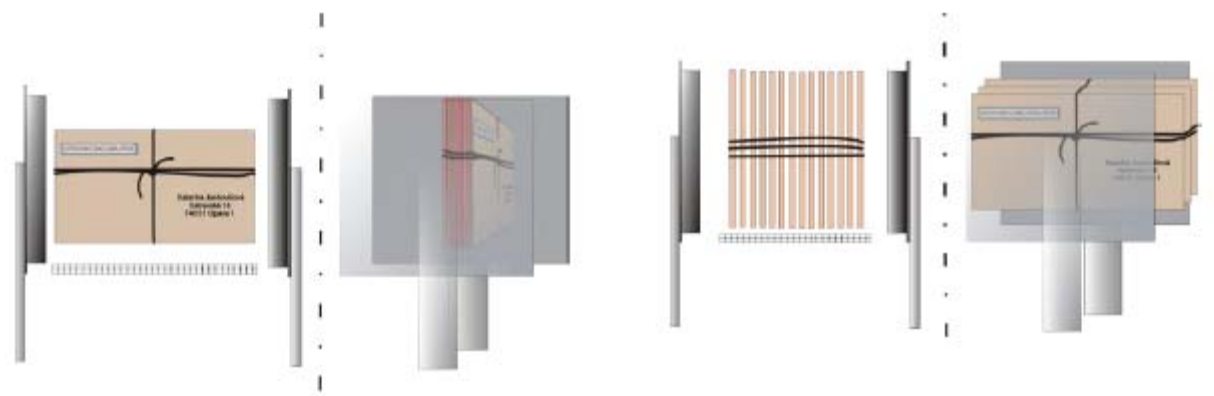

situation 1

situation 2
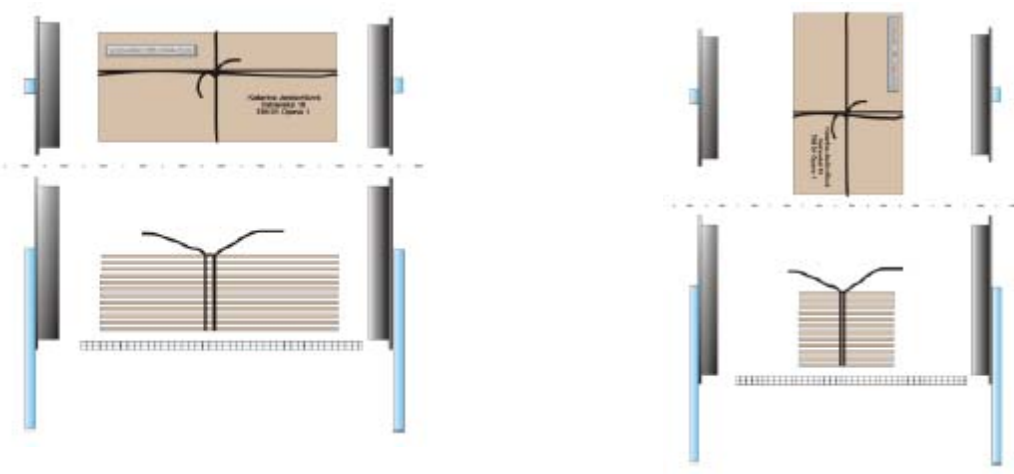

situation 3

situation 4

Figure 15. Configurations of the letters bundles

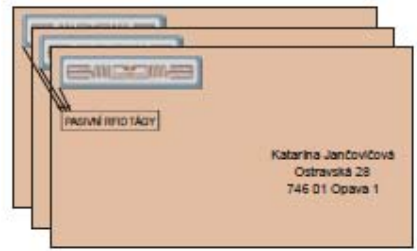

set A

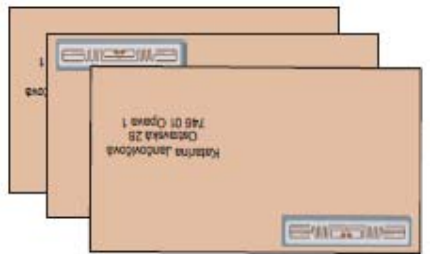

set B

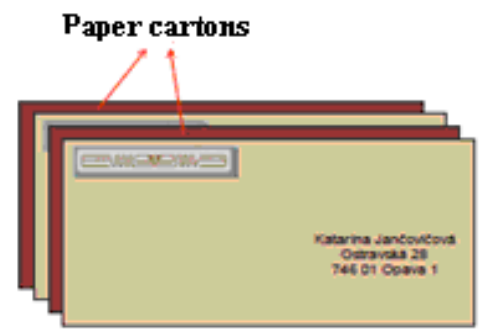

set $\mathrm{C}$

Figure 16. Several sets of the letter bundles 
We have used two ways of transporting items via the gate:

1. Static transfer through the postal truck or conveyor, also examined the transport unit volumes, which are in a relative peace in terms of positioning items

2. Dynamic hand, respectively the manual transfer using human power - move with a rate shocks, which could help to read the labels in bundles better.

All the data recorded after the measurement time have become the subject of evaluation, and because of the large scale of the recorded data, there have been evaluated only the average and the cumulative results. Determining the accuracy of measurements based on the statistical characteristics - it is a statistical description, which expresses the degree of statistical variability of the file, it indicates the letter R, It indicates the difference between the largest and smallest value and in some extent we are able to denounce both the large inaccuracies in the measurement occurred. It is expressed by the formula $R=X_{\max }-X_{\min }$. In percentage terms inaccuracies modified formula looks as follows:

$$
Z=\left(\left(X_{\max }-X_{\min }\right) / \text { number_of_items }\right) * 100 \text {. }
$$

Basing on this formula, inaccuracies sets were compiled by chart positions.

Since the evaluation of this quantity of data with the graphic processing is substantially opaque (a sample can be figure 17. with a graphical evaluation, which is a preview of kits depending on the speed of transition between the antennae) and it is not possible to present all the results of the measurements on such a small space, only the basic results of the measurements have been summed up and the authors have focused only on some important findings.

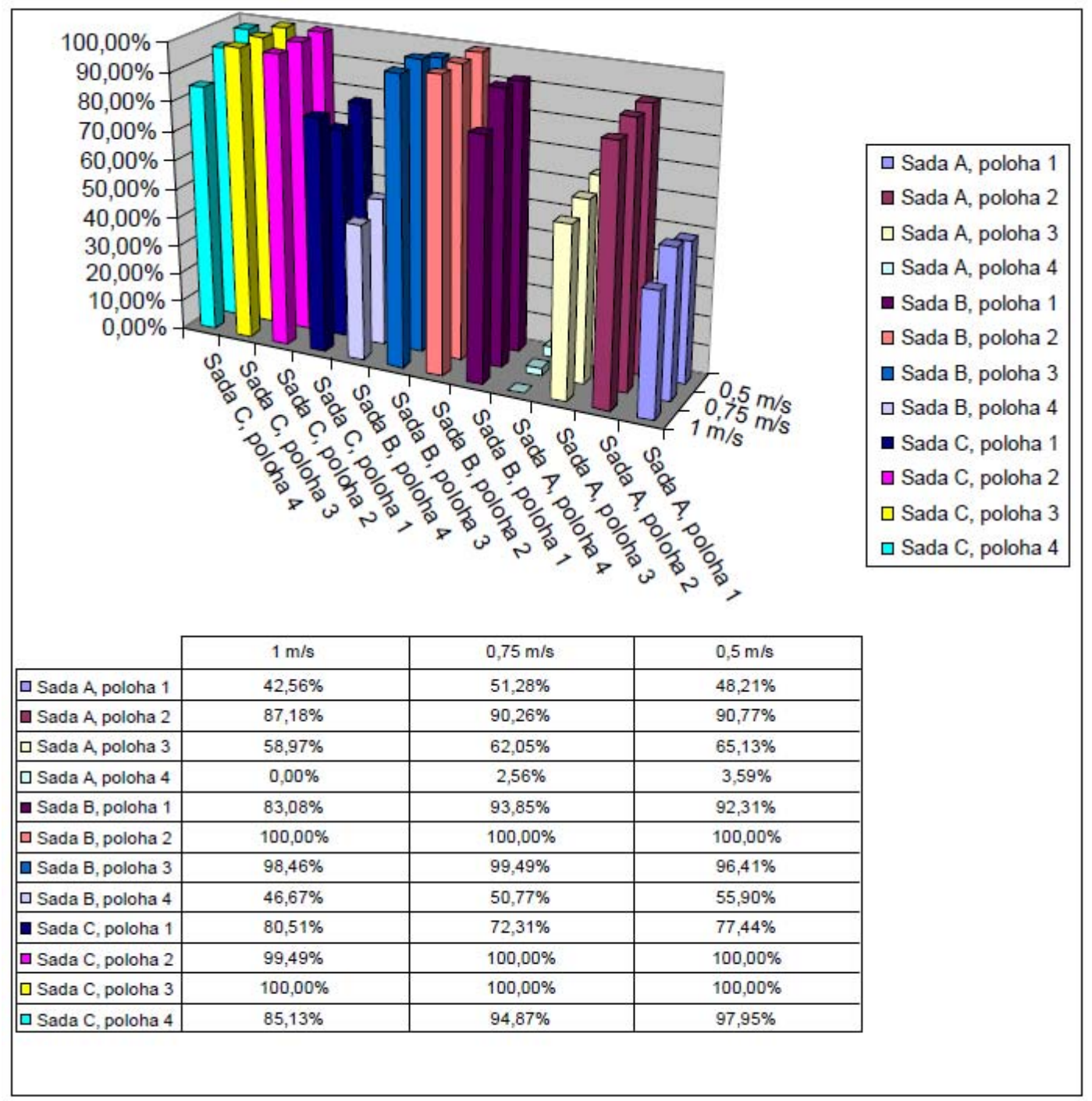

Figure 17. Final test results 
The measurement is made clear that some parameters are irrelevant in terms of readability, such as the speed of shipments run through the transition zone, readers are relatively independent (readability in an average of about $76 \%$ to $2 \%$ deviation, the readers distance is taken with a $77 \%$ deviation around $6 \%$ use conveyor with $80 \%$ deviation around $4 \%$, or manual switch $(94 \%$ with a deviation of about $2 \%)$.

Table 1. Basic dependency between the sets of readability and the situations

\begin{tabular}{|c|r|r|r|r|r|}
\hline Set & situation 1 & situation 2 & situation 3 & situation 4 & \multicolumn{2}{l|}{ average } \\
\hline A & $47,35 \%$ & $89,40 \%$ & $62,05 \%$ & $2,05 \%$ & $50,2 \%$ \\
\hline B & $89,74 \%$ & $\mathbf{1 0 0 , 0 0 \%}$ & $98,12 \%$ & $51,11 \%$ & $84,7 \%$ \\
\hline C & $76,75 \%$ & $99,83 \%$ & $\mathbf{1 0 0 , 0 0 \%}$ & $92,65 \%$ & $92,3 \%$ \\
\hline
\end{tabular}

It is interesting that in an evaluation of readability situations of the consignment the given readers run through the gate (table 1 upper part), in some cases it is sufficient and relatively uniformed (situation 2 and 3 , value of $100 \%$ ), while situation 4 is, for example, the readership in wide range of $2 \%$ up $92 \%$.

The overall success of the method of transition as the distance of antennae for different speed ranges from $81 \%-87 \%$, and has a major impact on readability, similar to the way the transition between the sets of antennae is relative stable ( $81 \%$ to $95 \%)$

Basing on the evaluation of the measurement data cannot be identified unambiguously, excluded or recommend for the use of this technology in practice. These measurements may be partly conditional on imprecision caused by a provisional Laboratories. It is unable to clearly provide the desired stable speed and position of shipments due to the antenna. The end result is, therefore, the lack of readability of RFID tags in a traditional way-now commonly used in practice in the post measurements, known as set A. Although in other cases, the readability is very high and almost $100 \%$ (set $\mathrm{C}$ or B), there are other aspects that significantly affect its use.

\section{Conclusions}

RFID is a very useful and exciting technology. It seems that everywhere one looks there is some article about RFID and the huge benefits, which are promised by this technology. Moreover, there are many examples that demonstrate how this technology is fulfilling its potential.

Basing on the measurements it can be concluded, with some exceptions that prove the rule, the closer they are to each antenna, the greater the success of reading RFID tags. Given the large dispersion of values it can be concluded that some elements are simply eliminated. They can, for example use the multiple counting gates, respectively antennae (eliminating the position of shipments), or the use of such specialty (bubble) envelopes for magnification air gap between consignments (as by set C)

This article deals with the identification of the postal items and transport units in logistic chain of postal operators. It has described the scheme of the transport process, including the planned technology and there is also a real postal process simulated in conditions close to operational. The article is a part of the projects described above, which, together with the afore-mentioned applications, are able to improve the learning process at the Department of Communications.

This article was created to support project named as:

KEGA 077-059ŽU-4/2010 "Implementácia nových technológii do vzdelávania (vytvorenie RFID laboratória ako podporného prvku pre vzdelávanie)" - "Implementation of new technologies in education (create RFID lab in support of both education)"

KEGA 089-068ŽU-4/2010 "Aplikácia RFID pri sledovaní pohybu diplomových a bakalárskych prác $v$ rámci univerzitného campusu" - "Application of RFID in tracking Theses within the university campus" Centre of Excellence for systems and intelligent transport II (048/2009/2.1/OPVaV, Aktivita 1.4) - ITMS 26220120050

\section{References}

1. Hunt, V. D., Puglia, A., Puglia, M. (2006). RFID: A Guide to Radio Frequency Identification. New Jersey: John Wiley \& Sons.DOI: 10.1002/9780470112250.ch1

2. Švadlenka, L. (2007). RFID in postal and courier services. In B. V. S., PRASAD, Selvan, KALAI, (Eds.). Supply chain management in services industry: an introduction. 1st edition, (pp. 68-74). Hyderabad (India): Icfai Books. 
3. Thornton, F., et al. (2006). RFID Security. Rockland: Syngres Publishing.

4. Tengler, J. (2010). Identification of postal items through RFID technology. Diploma paper, University of Žilina, Žilina, Slovakia.

5. Zelik, P. (2010). Mobile technology in postal transport. Dissertation thesis, University of Žilina, Faculty of Economic and Operation of Transport and Communication, Žilina, Slovakia.

6. Hofmann, L. (2011). UHF RFID technologie kreativní technologie bez mýtu, Odborný časopis pro vývoj a výrobu v oboru elektroniky DPS leden/únor. Creative Technology Without Myth, Professional Journal for the Development and Manufacturing in Electronics PCB, Volume (1), 80-81.

7. Kolarovszká, Z., Fabuš, J. (2011). Riadenie služieb IT u poskytovatel'ov univerzálnej poštovej služby v Európe (IT Service Management in Conjunction with the Universal Postal Service in Europe). In POSTPOINT 2011 "Open Market - A Challenge for Postal Services", Slovakia, September 19-20, 2011 (pp.114-122). Žilina, EDIS. 